\title{
Traduções osmosemióticas: escutando em alemão, falando em inglês e desenhando em português
}

\section{Osmosemiotic translations: listen to German, speaking English and drawing in Portuguese}

\author{
“Oh, be some other name! What's in a name? \\ That which we call a rose \\ By any other name would smell as sweet;" \\ (ShaKeSPEARE, W. Romeo and Juliet, Ato II,
}

Cena II)

\section{Paula Mastroberti*}

Resumo: Ensaio, a partir de Michel Foucault, Nicolas Bourriaud e da semiótica de Charles S. Peirce, entre outros, algumas reflexões sobre minha experiência como autora brasileira convidada pelo Instituto Goethe para produzir uma história em quadrinhos que de alguma forma refletisse a experiência de ter residido durante 30 dias em Berlim. A narrativa resultante, cujo título fiz questão de manter em alemão, Zwei Rosen in Berlin, procura justamente expressar não apenas o entrecruzamento linguístico vivido (português, inglês e alemão, idiomas dos quais me servi), mas também imaginário, em que o conhecido conto dos irmãos Grimm, Schneeweißchen und Rosenrot, conhecido por nós, brasileiros, como Rosa Branca e Rosa Vermelha, ao ser versado para a linguagem dos quadrinhos, adquire outras tonalidades ao assumir por cenário a capital alemã.

Palavras-chave: Quadrinhos; contos de fadas; tradução intersemiótica; cultura germânica.

* Professora do Instituto de Artes da UFRGS, escritora e artista gráfica. 
MASTROBERTI, P. - Traduções osmosemióticas: escutando em alemão, falando em inglês e desenhando em português

Abstract: This essay elaborates, based on Michel Foucault, Nicolas Bourriaud and the semiotics of Charles S. Peirce, among others, some reflections on my experience as a Brazilian author invited by the Goethe Institut to produce a comic book that somehow reflected the experience of having resided for 30 days in Berlin. The resulting narrative, whose title I made sure to keep in German, Zwei Rosen in Berlin, seeks precisely not only to express the language intersection between Portuguese, English and German (the languages of which I made use there), but also the development of the imaginary I have experienced. Thus, the well-known Grimm tale Schneeweißchen und Rosenrot, or White Rose and Red Rose, acquires other hues when rendered into the language of comics and having the German city as its setting.

Keywords: Comics; fairy tales; intersemiotic translation; german culture.

Em As palavras e as coisas ${ }^{1}$, Michel Foucault lança-se a refletir sobre a arbitrariedade do signo como representação. Suas reflexões concernem à palavra, embora, dentro de um estudo comparatista de base histórica, ele inclua até mesmo a moeda como atribuição de valor e, por conseguinte, como significante. Para a reflexão que apresento neste espaço interessará o modo como ele elucida os percursos evolutivos da escrita como registro da língua falada, das demandas por uma gramática geral abrangente de toda variação linguística, (tarefa impossível, como Foucault não deixará de mencionar).

Ao chegar nesse ponto, destaco uma frase do filósofo, na qual ele diz: “o que torna as línguas estrangeiras opacas umas às outras e tão difíceis de traduzir, mais que a diferença de palavras, é a incompatibilidade de sua sucessão"2 . É possível que esse seja o mesmo motivo pelo qual, por oposição, os discursos visuais, tais como o desenho ou a pintura, predisponham-se a ser amplamente compreendidos ${ }^{3}$ : a sucessão de traços, de manchas coloridas,

\footnotetext{
${ }^{1}$ Foucault 2007.

2 FOUCAULT 2007: 115.

3 Predispor-se significa falar de uma compreensão em um nível simples e parcial, fundamentado na representação do real ou objeto pré-existente. Não entro aqui, certamente,
}

TradTerm, São Paulo, v. 27, Setembro/2016, pp. 39-49

www.usp.br/tradterm

http://www.revistas.usp.br/tradterm/index 
MASTROBERTI, P. - Traduções osmosemióticas: escutando em alemão, falando em inglês e desenhando em português

enfim, a produção de uma sintaxe visual passa em primeiro lugar por uma cognição do corpo (da mão, do gesto, da sensibilidade fisiológica ocular), produzindo significados imediatos a partir de dados imanentes ou substanciais (icônicos, remáticos, qualissígnicos ${ }^{4}$ ). Embora a representação pictográfica possa ser, tanto quanto a palavra, convencional ou simbólica, indireta ou indicial, sua aderência à coisa representada ${ }^{5}$ e sua composição diagramática ${ }^{6}$, ainda que arbitrária e complexa, resulta minimamente compreensível por praticamente qualquer mente humana em sãs condições físicas. Trata-se de uma língua irradiada pela totalidade de um corpo, feita para ser lida e compreendida por uma mente-corpo. Nem por isso a linguagem pictográfica prescinde de conhecimento ou de conceitos para sua produção ou interpretação, tal como se requer para os usos competentes do verbo. Também não significa que ela será compreendida de forma absoluta, produzindo uma única e irrevogável exegese. Contudo, diferente da língua falada e escrita, o idioma plástico conversa, numa primeira instância, com nossa emoafetividade através de dados estéticos e, mais diretamente, com nosso imaginário visual.

É possível dizer que uma concepção pictográfica será tanto mais opaca quanto mais ela se aproximar de um conceito de escritura ${ }^{7}$. Será por isso que, para uma dada localidade cultural, um objeto visual produzido por outra corre o risco de parecer destituído de sentido ${ }^{8}$ ? Cores, formas, marcas pictóricas ou

nas variações de estilo, nem nos valores iconográficos (metafóricos ou alegóricos) e culturais implícitos numa representação visual, muitas vezes incognoscíveis para aqueles que não estão familiarizados com as especificidades do código.

${ }^{4}$ PEIRCE 2005.

${ }^{5}$ Refiro-me aqui à figuração em seu sentido lato, ou seja, a um tipo de configuração pictográfica que aponte para um dado objeto real ou pré-existente.

${ }^{6}$ DeleUZe 2007.

7 Verificamos isso facilmente quando pensamos nas concepções de Vassily Kandinsky, por exemplo, para composição de uma pintura abstrata (KANDINSKY 2012).

${ }^{8}$ Pensemos, por exemplo, na pichação e no grafite, ou nas artes tribais, cujos códigos são compreensíveis apenas para iniciados; ou ainda no modo como algumas culturas indígenas

TradTerm, São Paulo, v. 27, Setembro/2016, pp. 39-49

www.usp.br/tradterm

http://www.revistas.usp.br/tradterm/index 
MASTROBERTI, P. - Traduções osmosemióticas: escutando em alemão, falando em inglês e desenhando em português

gráficas, podem ser reconhecidas, talvez apreciadas; mas a sintaxe diagramática que modula esses elementos, quanto mais desloca seus significados para os níveis convencionais (simbólicos), quanto mais depende de um conceito anterior à sua configuração (abstraindo-se), menos compreensível será ao olhar leigo ou estrangeiro. Nesse sentido ela se aproxima das variações idiomáticas e suas atribuições significativas, igualmente dependentes de valores simbólicos e de conceitos gramaticais e fonéticos.

A linguagem dos quadrinhos é frequentemente categorizada como uma facilitadora da leitura do código verbal. Essa afirmação deve ser, contudo, relativizada com respeito ao que eu disse acima. Para que a parte figurativa ou visual do discurso híbrido que define o gênero seja compreendida, ou para que conduza à compreensão do todo discursivo, é preciso que seus elementos pictográficos constituam parte do campo significativo e cultural conhecido pelo leitor.

Quando fui convidada pelo Instituto Goethe de Porto Alegre9 para participar do seu projeto de intercâmbio cultural para produção de uma história em quadrinhos ${ }^{10}$, foi o nome com que o designaram a minha primeira motivação: osmose. Sabemos a que fenômeno biológico ela se refere ${ }^{11}$. E sabemos a que esta palavra objetivaria, por derivação. A relação osmótica não metaforiza aqui, de modo algum, uma operação de tradução (traduzir a cultura alheia para uma cultura local), mas quase o oposto: fazer emergir, através da fricção linguística e cultural, o intraduzível. A ação de traduzir não

reagiam às imagens modernas produzidas pelo cinema e pela fotografia, e até mesmo a pintura tradicional.

${ }^{9}$ Seu diretor no período era o Sr. Reinhard Sauer.

10 Essa produção foi publicada na antologia bilíngue Osmose: Brasil e Alemanha em quadrinhos, Editora Libretos, 2013.

${ }^{11} \mathrm{Em}$ suma, a osmose é um fenômeno de intercâmbio físico-químico que permite, através da água, a troca de nutrientes e o equilíbrio dos níveis de concentração citoplasmática entre células.

TradTerm, São Paulo, v. 27, Setembro/2016, pp. 39-49

www.usp.br/tradterm

http://www.revistas.usp.br/tradterm/index 
MASTROBERTI, P. - Traduções osmosemióticas: escutando em alemão, falando em inglês e desenhando em português

se faz por equivalências, mas por compensações assimétricas. Uma tradução não equivale à leitura do original, mas é sempre uma protoleitura ${ }^{12}$, realizada pelo mediador da língua ${ }^{13}$.

A operação mais próxima à metáfora que resume os objetivos do Projeto poderia ser semiotizar, derivada da função que Nicolas Bourriaud atribui ao artista contemporâneo - concebido como um semionauta ${ }^{14}$. Com base nisso, ao produzir o meu conto gráfico, menos me preocupei em traduzir a minha experiência cultural em Berlim do que em semiotizar essa experiência de modo a retroalimentar os sistemas envolvidos como um todo: eu, minha cultura, o projeto, a cidade de Berlim para onde emigrei, e a cultura alemã, de um modo geral.

Pouco preocupada em traduzir, da mesma forma não determinei a escritura ou o idioma que substanciaria a minha história. Uma das condições para ser escolhido a participar do Projeto era não falar alemão. Tomei-a por premissa: a partir daí a localização da língua tornou-se secundária, ou melhor, meu interessese voltaria para a sua desterritorialização. Brasileira, falante de português, em Berlim me comunicava basicamente em inglês (às vezes em francês) ouvindo e lendo em alemão. Eram férias de verão, e o bairro onde eu residi por quase um mês fervilhava de turistas: muitos idiomas se entrelaçavam ao longo da Kurfürstendamm ${ }^{15}$.

Outra diretriz, pré-estabelecida por mim, seria a escolha temática, a ser trabalhada em torno de um conceito osmótico. Minha ligação com a Alemanha vem sobretudo através dos contos-de-fadas (märchen). Selecionei

\footnotetext{
12 Protoleitura é um conceito gerado por mim em minha dissertação de mestrado e designa a leitura gráfica-visual, mediadora do texto literário ao olhar daquele que lê, ao mesmo tempo em que localiza obra e receptor em dado tempo e espaço. (MASTROBERTI 2007: 75).

13 “A tradução é, por essência, um deslocamento: movimenta o sentido de um texto de uma forma linguística para outra e revela todos os seus tremores." (BoURRIAUD 2011: 52).

14 Para Bourriaud, o artista é um semionauta que “inventa trajetórias entre signos." (BOURRIAUD 2009: 151).

${ }^{15}$ Uma das principais avenidas de Berlim e centro comercial internacional da cidade.
}

TradTerm, São Paulo, v. 27, Setembro/2016, pp. 39-49

www.usp.br/tradterm

http://www.revistas.usp.br/tradterm/index 
MASTROBERTI, P. - Traduções osmosemióticas: escutando em alemão, falando em inglês e desenhando em português

Schneeweißchen und Rosenrot (literalmente, Branca Neve e Rosa Vermelha, aqui no Brasil conhecido como Rosa Branca e Rosa Vermelha) em virtude do personagem urso, símbolo da capital alemã ${ }^{16}$. Outra motivação importante foi a possibilidade de explorar as cores da bandeira desse país (vermelho, amarelo e negro), através dos índices cromáticos presentes nos nomes das duas irmãs, somadas a do urso (em preto na bandeira e na minha configuração): apenas o nome da personagem Schneeweißchenfoi alterado para Rosengelb (Rosa Amarela). 0 título do conto (que fiz questão de colocar em alemão) anuncia o intertexto: Zwei Rosen in Berlin (Duas rosas em Berlim).

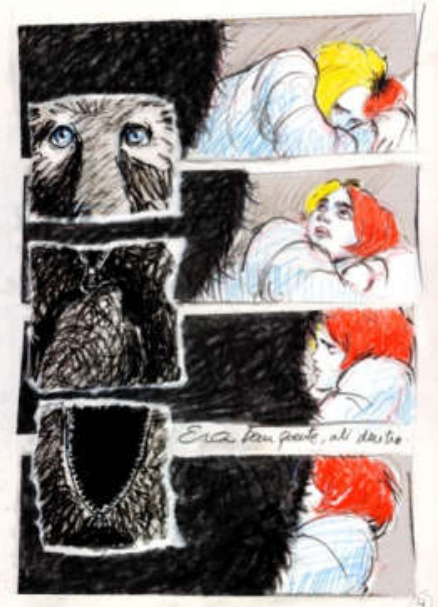

Fig. 1 Prancha 4: o urso e a paleta de cores.

A partir daí, outros significados e significantes se entrecruzam no discurso visual: a transposição de um conto cuja origem se perde nos tempos para a contemporaneidade, resultando num conto totalmente novo; a sua apropriação por uma autora brasileira e o modo como ela incorpora a história

\footnotetext{
${ }^{16}$ Trata-se da história de duas irmãs que, numa noite de inverno, abrigam em sua casa um urso, com consentimento da mãe. Terminado o inverno, o urso vai embora e as jovens só voltarão a vê-lo após algumas peripécias vividas em torno de um gnomo estranhamente malagradecido e rabugento, quando descobrem que o urso era, na verdade, um príncipe enfeitiçado.
}

TradTerm, São Paulo, v. 27, Setembro/2016, pp. 39-49

www.usp.br/tradterm

http://www.revistas.usp.br/tradterm/index 
MASTROBERTI, P. - Traduções osmosemióticas: escutando em alemão, falando em inglês e desenhando em português

e a devolve à cultura alemã, equilibrando os dados culturais e dissolvendo suas fronteiras através de uma operação osmótica traduzida pelas fotografias que registraram, dia após dia, o justo local de aderência entre o meu corpo e o da cidade; essas fotografias que são também a comprovação de que a Berlim vivida por mim é tão única quanto a subjetividade que nela habitou. Muitos desses rastros de aderência foram diretamente transferidos para a versão gráfica, na aplicação dessas mesmas fotografias. ${ }^{17}$ Essas não são necessariamente imagens fiéis de Berlim: antes, derivam do jogo gráfico e interativo que eu estabeleci com a cidade.

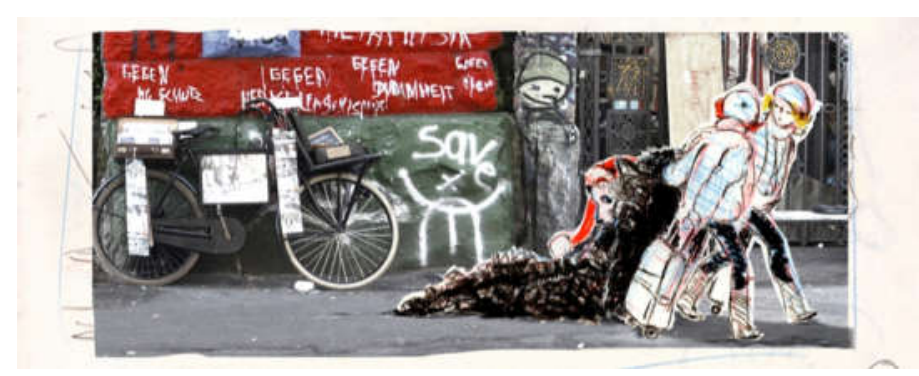

Fig. 2: Prancha 10, detalhe: mesclagem da fotografia com desenho.

Como veem, eu estava configurando minha narrativa a partir de uma grade semântica - visual e verbal - planejada previamente, cujas conotações envolvem dados simbólicos e poéticos que contaminam a linguagem híbrida dos quadrinhos e se encontram além das questões tradicionais que envolvem uma tradução. $\mathrm{E}$, dado que meu propósito era falar de um processo de trocas (físicas e simbólicas), muito mais do que de um objeto pronto e destacado de seu contexto de produção, o mesmo acordo teve que ser feito em relação ao roteiro. Uma história alemã (refiro-me simultaneamente ao conto e a minha experiência), contada por uma brasileira que mal ultrapassou o dankeschönou o bis bald, mas serviu-se abundantemente do inglês, não seria honesta se não revelasse justamente

\footnotetext{
${ }^{17}$ Em vez de desenhar os cenários a partir do referencial fotográfico, eu apliquei recortes das fotografias diretamente sobre os quadrinhos, usando recursos digitais.
}

TradTerm, São Paulo, v. 27, Setembro/2016, pp. 39-49

www.usp.br/tradterm

http://www.revistas.usp.br/tradterm/index 
MASTROBERTI, P. - Traduções osmosemióticas: escutando em alemão, falando em inglês e desenhando em português

esse intercâmbio igualmente intraduzível, resultante desse roçar de membranas linguísticas. Por isso, o roteiro de Zwei Rosen in Berlin foi escrito em três línguas, e inscrito em meio às artes de modo que as frases apontassem a si mesmas e a sua própria opacidade, emanada através do contato de umas com as outras. Por isso, justaposições, contraposições presentes no próprio grafar da escritura.

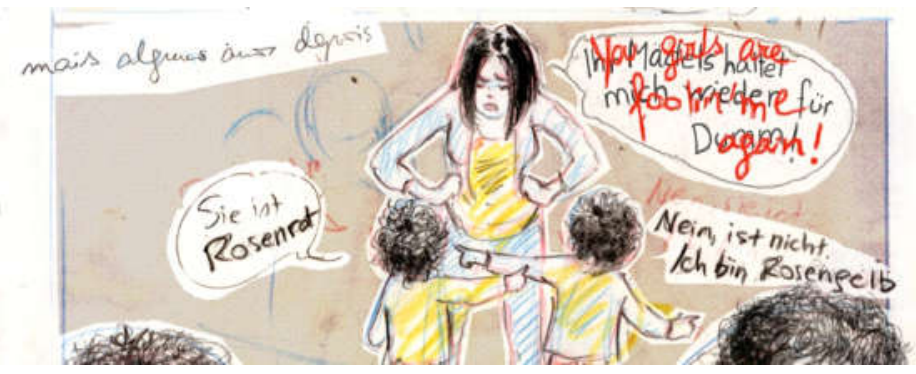

Fig. 3 Prancha 8 , detalhe: texto pluridiomático em palimpsesto.

É claro que podemos falar em um objeto resultante, e de um equilíbrio apaziguador: após a ebulição das linguagens visuais e verbais, o que até a mim surpreendeu foi a convergência inesperada entre a temática selecionada (o nome do projeto e o conto de fadas alemão) e os processos desenvolvidos para contá-los. Para apreciar Zwei Rosen in Berlin, não se faz necessária nenhuma tradução; pois é justamente nos interstícios entre o verbo e a imagem, entre o conto antigo e sua recriação, entre as línguas e as culturas envolvidas, entre a minha pessoa e a cidade, lá onde nenhuma tradução é possível, que ele será compreendido.

\section{Referências}

BourRiaUd, N. Estética relacional. Martins Fontes, 2009.

BourriAud, N. Radicante. São Paulo: Martins Fontes, 2011. 
MASTROBERTI, P. - Traduções osmosemióticas: escutando em alemão, falando em inglês e desenhando em português

Deleuze, G. Pintura: el concepto de diagrama. Buenos Aires: Cactus, 2007. Foucault, M. As palavras e as coisas. São Paulo: Martins Fontes, 2007. Goethe Institut (Coord). Osmose: Brasil e Alemanha em quadrinhos. Porto Alegre: Libretos, 2013.

KANDINSKY, W. Ponto e linha sobre plano. São Paulo: Martins Fontes, 2012.

MASTROBERTI, P. Peter Pan e Wendy em versão brasileira: uma janela aberta para o livro como suporte híbrido. Dissertação de mestrado (Mestrado em Teoria da Literatura). Faculdade de Letras da Pontifícia Universidade Católica do Rio Grande do Sul (PUCRS), Porto Alegre, 2007. Disponível em: http://tede.pucrs.br/tde_busca/arquivo.php?codArquivo=1346. Acesso em: dez. 2012.

PEIRCE, C. S. Semiótica. São Paulo: Perspectiva, 2005. 
MASTROBERTI, P. - Traduções osmosemióticas: escutando em alemão, falando em inglês e desenhando em português

\section{Anexo}

1. Página do conto gráfico Zwei Rosen in Berlin (Fonte: arquivo da autora). Abaixo, segue o excerto mais ou menos correspondente em alemão do conto popular Schneeweisschen und Rosenroth conforme originalmente compilado por Jacob e Wilhelm Grimm no volume 2 da obra Kinderund Haus-Märchen, editada pela primeira vez em 1857, seguido de minha tradução livre:

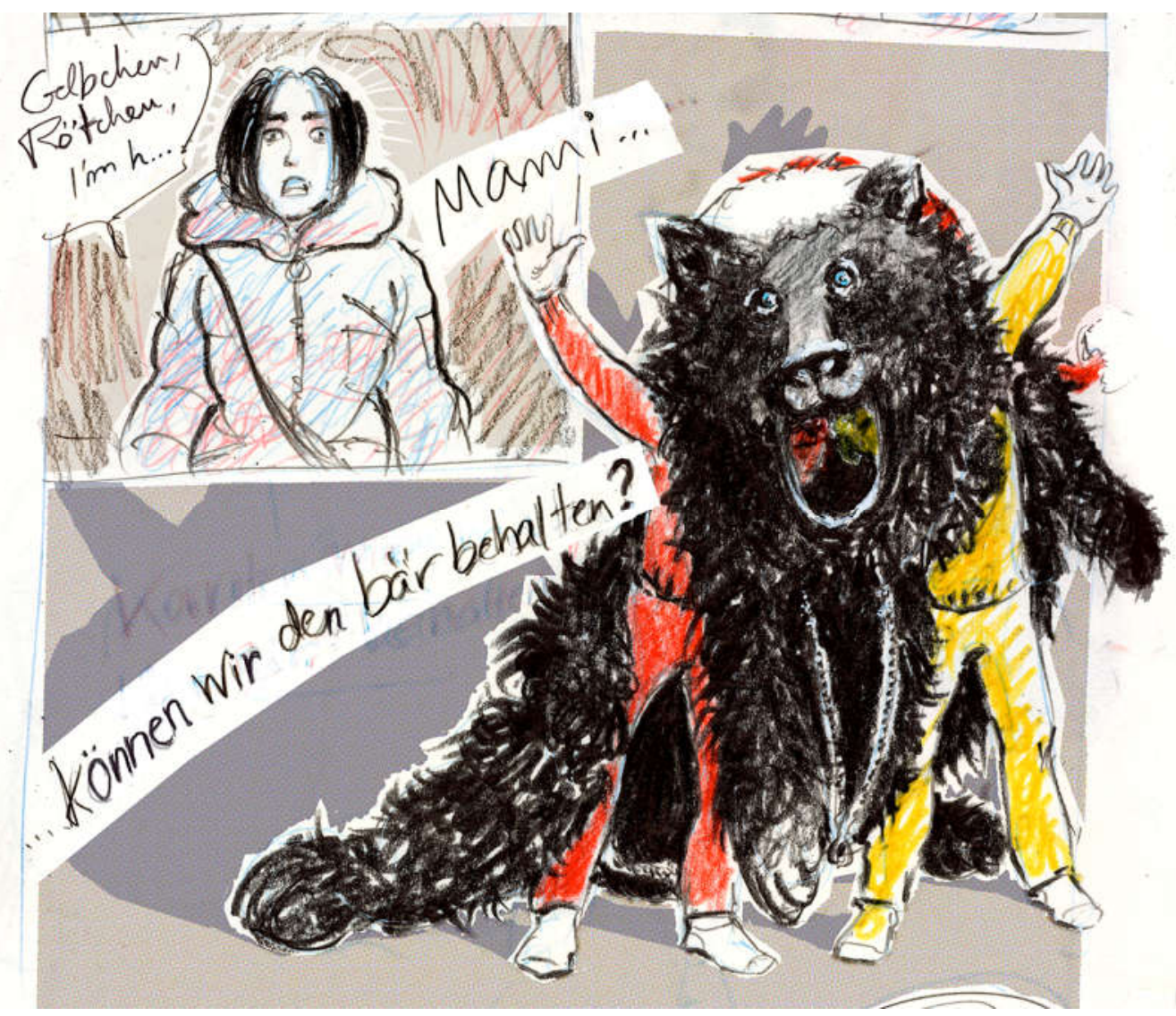

Tradução: Quadro 1: "Gelbchen, Rötchen, cheg..." Quadro 2: "Manhê... a gente pode ficar o urso?"

"Von nun an kam der Bärjeden Abend zu der bestimmten Stunde, legte sich an den Herd und erlaubte den Kindern Kurzweil mit ihm zu treiben, soviel sie wollten; und sie waren so gewöhnt an ihn, daß die Thüre nicht eher 
MASTROBERTI, P. - Traduções osmosemióticas: escutando em alemão, falando em inglês e desenhando em português

zugeriegelt ward, als bis der schwarze Gesell angelangt war." ["Dali em diante, o urso veio todas as noites à mesma hora. Deitando-se junto ao fogo, permitia que as crianças se divertissem com ele o quanto quisessem; e elas estavam tão acostumadas com ele que não trancavam a porta até que o seu amigo peludo e negro tivesse chegado."]

TradTerm, São Paulo, v. 27, Setembro/2016, pp. 39-49

www.usp.br/tradterm

http://www.revistas.usp.br/tradterm/index 